\title{
Heat Stroke: Emergency Medicine Simulation Scenario
}

\author{
Karen Angus $^{1}$, Michael Parsons ${ }^{2}$, Adam Dubrowski ${ }^{3}$ \\ 1. Discipline of Emergency Medicine, Memorial University of Newfoundland 2. Emergency Medicine, \\ Memorial University of Newfoundland 3. Emergency Medicine, Pediatrics, Memorial University of \\ Newfoundland
}

$\square$ Corresponding author: Adam Dubrowski, adam.dubrowski@gmail.com Disclosures can be found in Additional Information at the end of the article

\section{Abstract}

Simulation-based medical education is an evolving field. In emergency medicine, the use of simulation has been demonstrated to improve learner knowledge and skills as well as patient outcomes, to a smaller degree [1]. In this report, we describe a simulation training session used to familiarize emergency medicine residents with the presentation and management of classic (non-exertional) heat stroke using a human patient simulator.

Categories: Emergency Medicine, Medical Education

Keywords: heat stroke, simulation, residents, adult, emergency medicine

\section{Introduction}

Heat stroke can present in various ways and has no strict diagnostic criteria, other than a temperature of $40^{\circ} \mathrm{C}$ and evidence of neurological dysfunction [2]. The identification and diagnosis of heat stroke is challenging for learners, as its presentation can mimic other conditions, especially in its classic non-exertional form. Additionally, trainees in a location whose climate does not predispose to its presentation may not be exposed to this in a clinical context. However, it is an important environmental emergency with high rates of morbidity and mortality, and is universally fatal, if left untreated [3].

This technical report describes a simulation teaching session designed for a cohort of postgraduate emergency residency trainees in their third and final year of training at Memorial University of Newfoundland. Its objectives include educating trainees about various ways in which classic heat stroke presents, the management of heat stroke with regards to techniques of cooling, and potential complications arising from heat stroke and its treatment.

Received 04/28/2014 Review began 04/29/2014 Review ended 05/06/2014 Published 05/06/2014

\section{(c) Copyright 2014}

Angus et al. This is an open access article distributed under the terms of the Creative Commons Attribution License CC-BY 3.0., which permits unrestricted use, distribution, and reproduction in any medium, provided the original author and

\section{Technical Report}

The simulation training session is conducted in a lab using a high-fidelity mannequin simulator. This particular simulation utilizes a Gaumard Noelle S575 human patient simulator.

Prior to the session, we develop a stepwise, detailed scenario template. The template is submitted to the simulation lab's technical staff, who then program the mannequin and supply required materials for the scenario's execution. Table 1 makes references to Figure 1 and Figure 2, which provide additional information. 


\section{Cureus}

\section{Pre-scenario}

You are an ER physician in a tertiary care hospital. Subspecialty back-up is available. A 75-year-old woman is brought in via ambulance agitated and confused. A friend had gone over to invite her out for a summer picnic and found her lying on the ground.

History

Allergies None

Medications Quetiapine, ramipril, metoprolol, ASA, Lipitor

PMHx Chronic paranoid schizophrenia, HTN, dyslipidemia

Other

T $39^{\circ} \mathrm{C}$ axillary / HR120 / BP80/50 / RR 26 / SpO2 99\% RA; pt is confused, agitated, slurring speech with inappropriate words.

HEENT Dry mucous membranes

CNS Pupils 3mm, equal, reactive; eyes open to command (E3); moving limb (M6), inappropriate words (V3) = GCS 12

Chest Bilateral crackles, normal HS

Abdomen Benign

Expected Actions

Actions

Initiate IVs

Connect to cardiac monitor, order EKG

May start supplemental $\mathrm{O} 2$

Request rectal temperature

Order IV NS 1L bolus

Order Foley - minimal urine output

Order labs - electrolytes, BUN, creatinine, complete blood count, liver function panel, arterial blood gas, serum lactate, blood/urine cultures, urinalysis, coagulation panels, cardiac troponins

Begin scenario

Objective 1: Airway / Breathing

Stage Vitals

Expected actions

Pt's

respiratory

status

$\mathrm{T} 42^{\circ} \mathrm{C}$ rectal (if requested) / HR 110 / BP90/60 / RR30s / SpO2

starts to $85 \%$ RA

Provide supplemental O2 100\%

deteriorate

Once

intubated

$\mathrm{T} 42^{\circ} \mathrm{C} / \mathrm{HR} 120$ / BP88/50 / SpO2 98\% 


\section{Cureus}

Objective 2: Making the Diagnosis

\begin{tabular}{|c|c|c|}
\hline Stage & Vitals & Expected actions \\
\hline $\begin{array}{l}\text { The results } \\
\text { of ordered } \\
\text { tests }\end{array}$ & $\begin{array}{l}\text { Liver function panel - normal Electrolytes, BUN, Cr - Na } 120 \text { / K5 } \\
\text { / Cl } 96 \text { / CO2 } 12 \text { / BUN } 25 \text { / Cr } 340 \text { CK/LDH - CK } 3560 \text { / LD } 210 \\
\text { Troponins - } 0.08 \text { Arterial blood gas - pH 7.18/pO2 68/pCO2 } \\
\text { 20/HCO3 } 10 \text { Complete blood count - WBC } 20 \text { / Hgb } 160 \text { / plts } \\
480 \text { Lactate - } 5.2 \text { Coagulation panels - normal Urine - normal } \\
\text { CXR - pulmonary edema (see fig 1) EKG - ST depressions, } \\
\text { tachycardia (see fig 2) }\end{array}$ & $\begin{array}{l}\text { Identify possible rhabdomyolysis, } \\
\text { pulmonary edema, cardiac } \\
\text { ischemia, metabolic acidosis, and } \\
\text { tie it all together to solidify the } \\
\text { diagnosis of heat stroke. Consider } \\
\text { differential diagnoses: sepsis, } \\
\text { anticholinergic toxicity. }\end{array}$ \\
\hline
\end{tabular}

Objective 3: Managing Heat Stroke

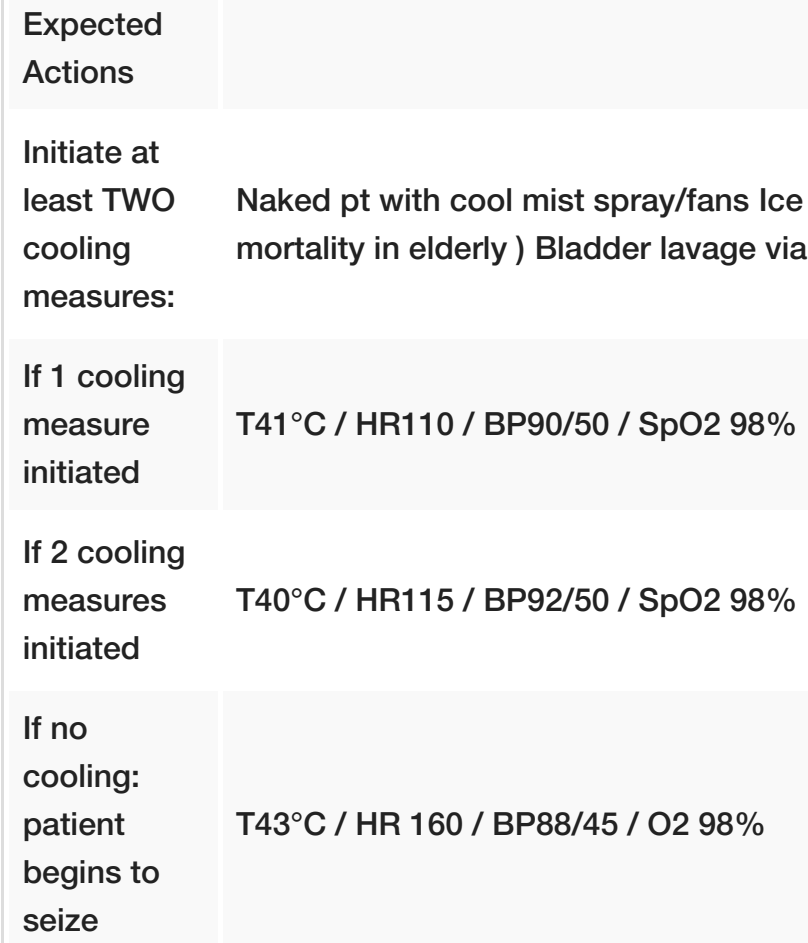

Objective 4: Managing Complications Of Cooling

The patient begins to shiver: Administer benzodiazepines. AVOID meperidine (anticholinergic).

Expected Vitals
Actions

If shivering

is

T39 ${ }^{\circ} \mathrm{C} / \mathrm{HR} 115$ / BP85/45 / O2 98\% - end scene

addressed

If shivering

is not

addressed

After 1 min: T40.5 ${ }^{\circ} \mathrm{C} / \mathrm{HR} 125$ / BP 85/50 / O2 99\% After 2 min: T41.5 ${ }^{\circ} \mathrm{C} / \mathrm{HR} 140$ / BP90/40 / O2 98\%

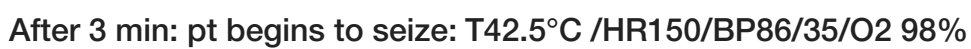




\section{Cureus}

Administer $\quad \mathrm{T} 41.5^{\circ} \mathrm{C} / \mathrm{HR} 115 / \mathrm{BP} 92 / 50 / \mathrm{SpO} 298 \%$

benzos

Scenario Conclusion (Endpoints)

Stabilization and transfer to ICU if: Cooling measures initiated Shivering is addressed

Termination of resuscitation in the setting of VT arrest if: No cooling initiated

TABLE 1: A stepwise, detailed scenario template to be submitted to the simulation laboratory technical staff, who program the mannequin and supply required materials for the scenario.

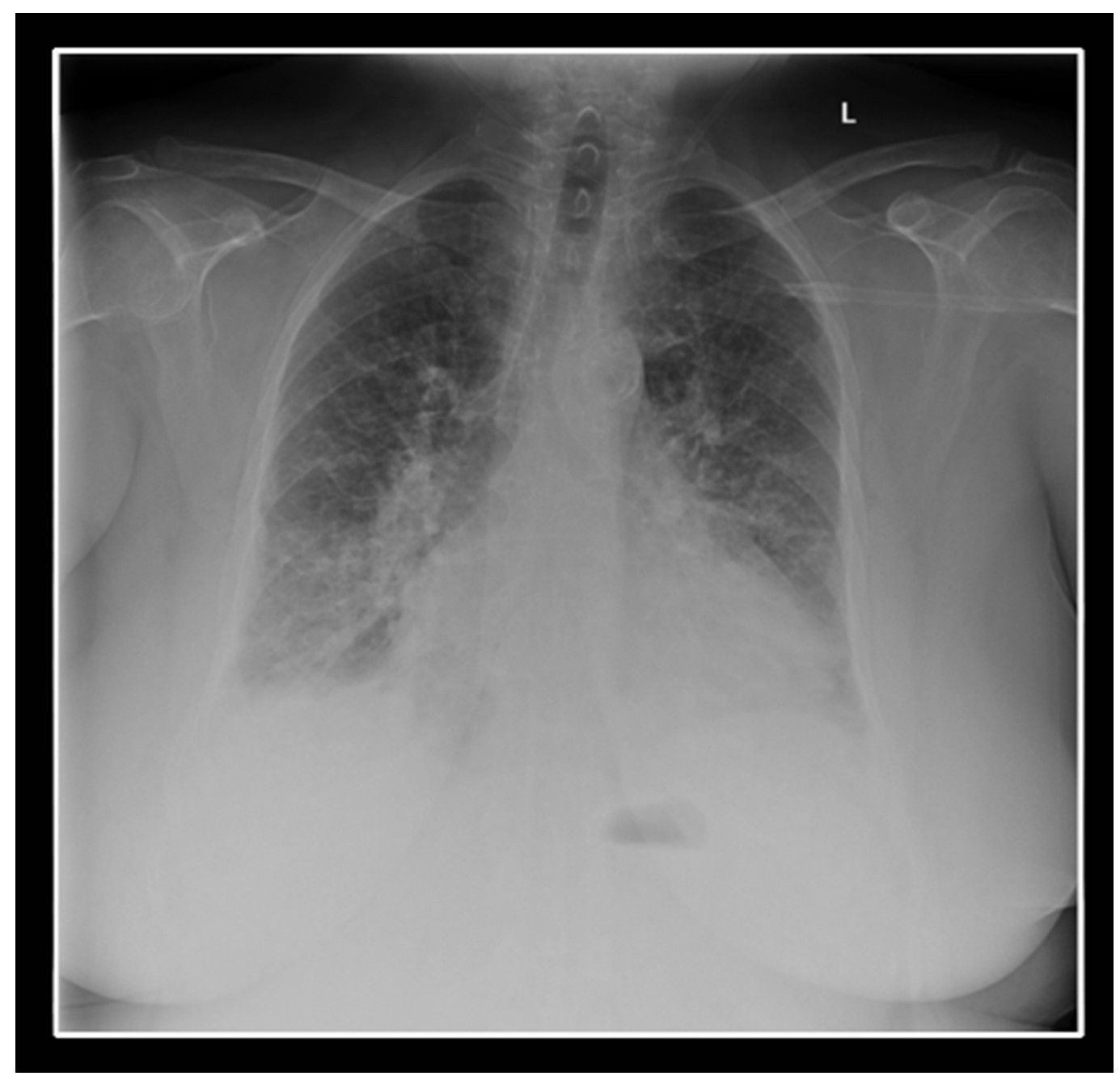

FIGURE 1: A chest radiograph, also known as a chest X-ray or CXR, demonstrating pulmonary edema. 


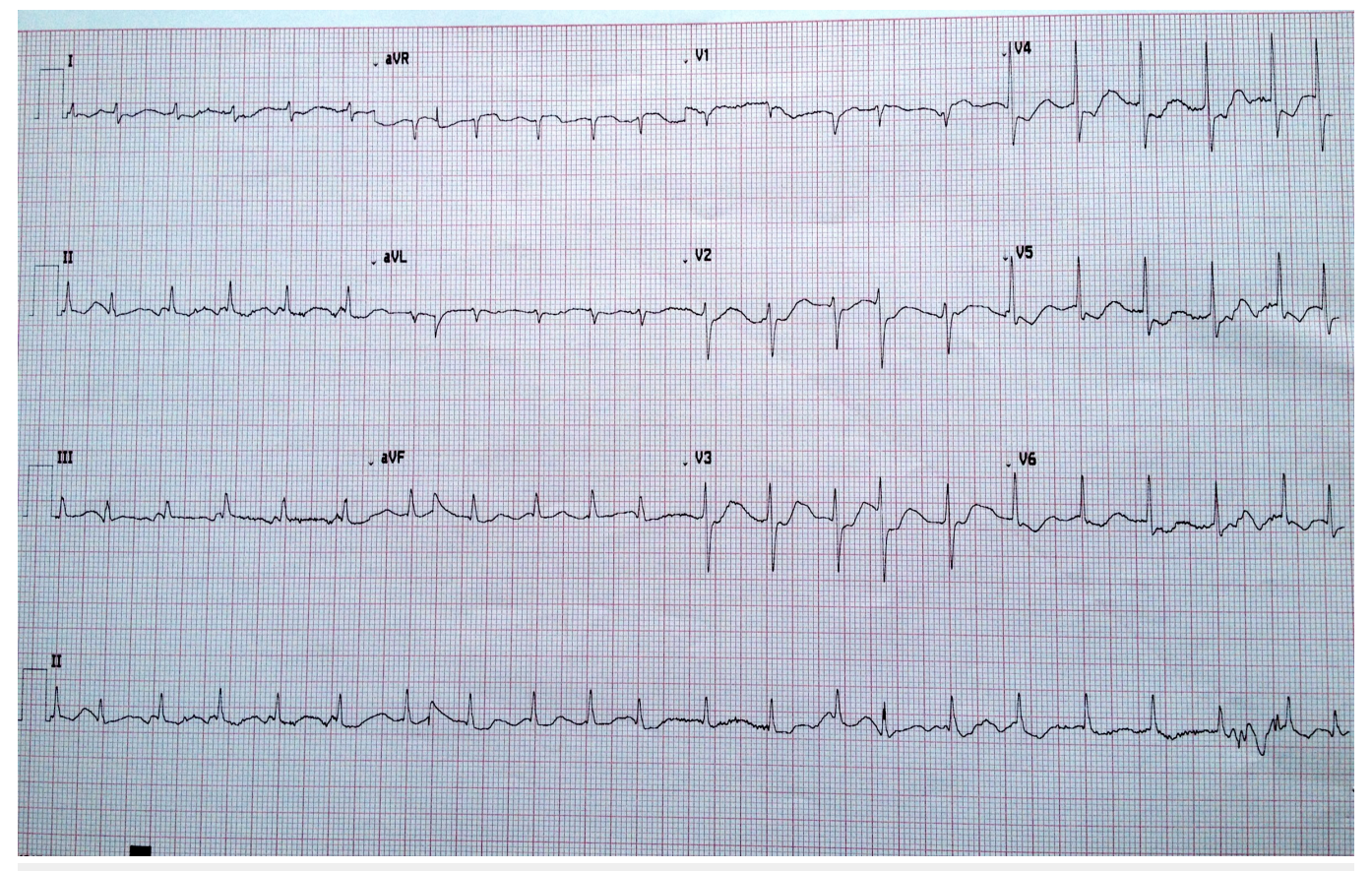

\section{FIGURE 2: An electrocardiogram (EKG or ECG) demonstrating cardiac ischemia with atrial fibrillation.}

To ensure a smooth experience for trainees, an instructor then completes a run-through of the scenario while acting as a trainee. Checklists are utilized during the scenario to provide an overall assessment of trainee competency. Two instructors are present, with one functioning as a scribe for a subsequent non-video debriefing and the other maintaining overall control of the scenario. In addition, we recruit a confederate to play the role of a nurse assisting the trainees.

\section{Pre-briefing}

A pre-briefing is held with the trainees before the case. During the pre-briefing, a team lead for the case is identified. Limitations of the simulation are reviewed, specifically addressing any technical issues with the mannequin and resource availability. In addition, the fiction contract - the agreement between participants and instructors to proceed as if the simulation is real while simultaneously acknowledging it is not - is revisited. Finally, trainees are advised that the scenario is strictly formative.

\section{Case}

The simulation case involves an elderly patient presenting with agitation and confusion to a tertiary care hospital after being discovered by a friend in her house. When they request, trainees are provided with details of the patient's allergies, medication list, and a past medical history that includes chronic paranoid schizophrenia, hypertension, and dyslipidemia.

At the beginning of the scenario, the patient is already connected to cardiac monitors with a full set of vital signs provided, indicating an axillary temperature of $39^{\circ} \mathrm{C}$, tachycardia, and hypotension. The scenario takes place in a resuscitation bay with a full complement of resuscitation cart, defibrillator, and difficult airway equipment available. Drugs necessary for advanced cardiac life support and rapid sequence intubation are also provided. In addition, props, such as ice packs and cool-mist sprayers, are provided if requested by the trainee. 
The trainees are then instructed to proceed with their evaluation of the patient.

\section{Debriefing}

Following the conclusion of the scenario, the trainees are provided with a formal debriefing. Care is taken during the debriefing to ensure that the number of debriefers is limited such that the debriefer-to-learner ratio does not exceed 1:1. This limit encourages learners to speak freely about issues they may have faced during the simulation. We use an in-house model developed based on based on frame-discovery [4] as well as the 3D model of debriefing [5] This approach focuses on an advocacy-inquiry technique aimed at uncovering the trainee's thought process, allowing us to address both errors of process and knowledge gaps.

\section{Post-scenario didactics}

A didactic session is held after the debriefing. This enables instructors to address the knowledge gaps identified through the scenario and debriefs, and gives trainees and opportunity to solidify and consolidate new knowledge gained as a result of the simulation exercise.

\section{Discussion}

The ability to diagnose and treat heat stroke is crucial for any emergency medicine physician; yet many emergency medicine trainees are not exposed to it in a clinical context due to the location of their training sites. A case simulation may thus be a valuable teaching tool in this context.

In this scenario, key learning objectives for trainees include:

1. Recognizing heat stroke and its multi-faceted presentation,

2. Management of heat stroke focused especially on cooling techniques,

3. Addressing potential complications of treatment.

During the post-scenario didactic session, we also address the effectiveness of various cooling techniques, contraindicated techniques (such as cold-water immersion specific to the case), and differentiating between classic (non-exertional) and exertional heat stroke and the differences in their respective management.

Developing the case scenario using a stepwise algorithm allows the simulation to flex according to decisions made by trainees. Implementing a run-through by an instructor also ensures that the case is not excessively demanding of the final-year resident, as well as enabling instructors to address any limitations of the scenario. Finally, utilizing a formal debriefing model as well as a post-scenario didactic session allows instructors to identify and address not just knowledge gaps but also errors of process committed by learners.

\section{Conclusions}

Teaching emergency medicine trainees to identify and management heat stroke via the use of simulation may be a valuable training tool. Here, we describe a stepwise algorithm developed to facilitate the execution of a scenario as well as an integrated teaching session incorporating simulation and didactics with components of debriefing included.

\section{Additional Information}




\section{Disclosures}

Human subjects: All authors have confirmed that this study did not involve human participants or tissue. Animal subjects: All authors have confirmed that this study did not involve animal subjects or tissue. Conflicts of interest: In compliance with the ICMJE uniform disclosure form, all authors declare the following: Payment/services info: All authors have declared that no financial support was received from any organization for the submitted work. Financial relationships: All authors have declared that they have no financial relationships at present or within the previous three years with any organizations that might have an interest in the submitted work. Other relationships: All authors have declared that there are no other relationships or activities that could appear to have influenced the submitted work.

\section{Acknowledgements}

This project was supported by Tuckamore Simulation Research Network and Emergency Medicine Educational Committee, Memorial University.

\section{References}

1. Ilgen JS, Sherbino J, Cook DA : Technology-enhanced simulation in emergency medicine: a systematic review and meta-analysis. Acad Emerg Med. 2013, 20:117-27.

2. Atha WF: Heat-related illness. Emerg Med Clin North Am. 2013, 31:1097-108.

3. Waters TA, Al-Salamah MA: Chapter 204. Heat Emergencies. Tintinalli's Emergency Medicine: A Comprehensive Study Guide. Tintinalli JE, Stapczynski JS, Ma OJ, Cline DM, Cydulka RK, Meckler GD (ed): McGraw-Hill, New York, NY; 2011.

4. Rudolph JW: Debriefing with good judgment: combining rigorous feedback with genuine inquiry. Anesth Clin. 2007, 25:361-76.

5. Zigmont JJ: The 3D model of debriefing: Defusing, discovering and deepening . Semin Perinat. 2011, 35:52-58. 